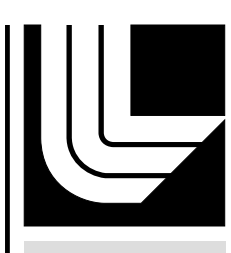

LAWRENCE LIVERM ORE N A TIO NAL LABORATORY

\title{
Radioargon production through the irradiation of calcium oxide
}

C. M. Egnatuk, S. R. Biegalski

December 5, 2012

Journal of Radioanalytical and Nuclear Chemistry 
This document was prepared as an account of work sponsored by an agency of the United States government. Neither the United States government nor Lawrence Livermore National Security, LLC, nor any of their employees makes any warranty, expressed or implied, or assumes any legal liability or responsibility for the accuracy, completeness, or usefulness of any information, apparatus, product, or process disclosed, or represents that its use would not infringe privately owned rights. Reference herein to any specific commercial product, process, or service by trade name, trademark, manufacturer, or otherwise does not necessarily constitute or imply its endorsement, recommendation, or favoring by the United States government or Lawrence Livermore National Security, LLC. The views and opinions of authors expressed herein do not necessarily state or reflect those of the United States government or Lawrence Livermore National Security, LLC, and shall not be used for advertising or product endorsement purposes. 
LLNL-JRNL-606692

Radioargon production through the irradiation of calcium oxide

Christine M. Egnatuk, ${ }^{1,2}$ Steven R. Biegalski ${ }^{2}$

${ }^{1}$ Lawrence Livermore National Laboratory, Livermore, CA, egnatuk1@1ln1.gov, phone:925-4243586 ,

${ }^{2}$ The University of Texas at Austin, Mechanical Engineering Department, Austin, TX 


\section{Abstract}

The production of radioargon through the irradiation of $\mathrm{CaO}$ was performed in an in-core facility within the The University of Texas at Austin MARK II TRIGA reactor. The major radioargon isotope produced was ${ }^{37} \mathrm{Ar}$ via the ${ }^{40} \mathrm{Ca}(\mathrm{n}, \alpha){ }^{37} \mathrm{Ar}$ reaction pathway. The $\mathrm{CaO}$ powder was vacuumed sealed in a quartz ampoule. The sample was irradiated in a Cd-lined Al alloy canister for 2 hours at $500 \mathrm{~kW}$. After the irradiation, the sample was counted using an HPGe detector five times with increasing count times. ${ }^{41} \mathrm{Ar},{ }^{42} \mathrm{~K},{ }^{43} \mathrm{~K}$, and ${ }^{47} \mathrm{Ca}$ were detected in the spectra. The induced activities of ${ }^{37} \mathrm{Ar},{ }^{39} \mathrm{Ar},{ }^{41} \mathrm{Ar},{ }^{42} \mathrm{~K},{ }^{43} \mathrm{~K}$, and ${ }^{47} \mathrm{Ca}$ were calculated using a 63-group energy-dependent neutron flux determined utilizing a neutron energy flux profile calculated from a MCNPX model of the TRIGA reactor core. The production ratios generated from the model allowed for the estimation of induced ${ }^{37} \mathrm{Ar}$ and ${ }^{39} \mathrm{Ar}$ activities through the measured induced activities of ${ }^{41} \mathrm{Ar},{ }^{42} \mathrm{~K},{ }^{43} \mathrm{~K}$, and ${ }^{47} \mathrm{Ca}$.

\section{Keywords}

argon, research reactor, noble gas, radioargon, neutron activation 


\section{Introduction}

Radioargon, specifically ${ }^{37} \mathrm{Ar}$, has been used for detector calibration. ${ }^{37}$ Ar sources have been used as a check source for neutrino experiments [1,2,3] because of the almost monoenergetic neutrino emitted during the decay to ${ }^{37} \mathrm{Cl}$. The ${ }^{37} \mathrm{Ar}$ samples produced through the irradiation of natural argon gas at The University of Texas at Austin were used to assist in the calibration of an ultra-low-background proportional counter [4]. The production capabilities of an ${ }^{37} \mathrm{Ar}$ sample with minimal other argon isotopes was examined through this experiment.

The University of Texas at Austin Nuclear Engineering Teaching Laboratory (NETL) has produced ${ }^{37} \mathrm{Ar}$ through gas activation [5] in a manner similar to the established radioxenon production procedure [6,7]. This method entails the irradiation of $0.58 \mathrm{~cm}^{3}$ of natural argon gas contained in a Teflon valve in the $3 \mathrm{~L}$ in-core canister. Irradiating natural argon gas via this method produced a small amount of ${ }^{37} \mathrm{Ar}$ with minimal impurities after the ${ }^{41} \mathrm{Ar}$ had decayed with a 109 minute half-life. In order to produce a pure ${ }^{37} \mathrm{Ar}$, the use of enriched ${ }^{36} \mathrm{Ar}$ gas could be used $[5,8]$. The irradiation of an enriched gas will also provide a larger induced activity of the desired radioargon isotope with minimal impurities.

The major production pathway for large-activity ${ }^{37} \mathrm{Ar}$ samples has been the irradiation of solid calcium-containing compounds. The irradiation of $\mathrm{CaO}$ is preferred by scientists with access to a fast reactor system $[1,2,3]$. The ${ }^{40} \mathrm{Ca}(\mathrm{n}, \alpha)^{37} \mathrm{Ar}$ pathway provides a sample with a limited amount of other argon isotopes. However, the threshold for this reaction is $0.5 \mathrm{MeV}$ and is not the optimal pathway to rely on with a thermal reactor. Past groups had in-core irradiations in fast reactors, with long irradiation procedures, and large solid samples.

In order to minimize the thermal activation of $\mathrm{Ca}$ isotopes within the UT TRIGA reactor, the Cdliner was used in the $3 \mathrm{~L}$ canister instead of the lead-lined canister. The modified flux profile allowed for a longer irradiation without compromising the activity of ${ }^{37}$ Ar produced. With the thermal activations minimized, the overall sample activity was easily in a range where health physics concerns were minimal.

The decision of which calcium-containing compound to use was based on ease of gas separation, minimizing the waste streams, and ability to withstand the heat generated during the irradiation within in Cd-lined facility, shown in Table 1. The major compounds considered were calcium oxide $(\mathrm{CaO})$, the metallic form, and calcium oxalate $\left(\mathrm{CaC}_{2} \mathrm{O}_{4}\right)$. Calcium oxalate allows for the easiest extraction of ${ }^{37} \mathrm{Ar}$ requiring only a liquid nitrogen-cooled charcoal trap and is relatively chemically inert. However, the compound breaks down to calcium oxide at temperatures of $200^{\circ} \mathrm{C}$, which could be reached during the irradiation. Metallic calcium has a high density of calcium and a high melting point. However, the separation of gas from the sample will be extremely difficult and requires multiple steps. Therefore, $\mathrm{CaO}$ was chosen for this experiment. $\mathrm{CaO}$ is chemically stable at high temperatures and has a high density of Ca. Also, the possibility of removing the produced argon gas is not as involved as the metallic $\mathrm{Ca}$. 


\section{Irradiation of $\mathrm{CaO}$}

A $2.0 \mathrm{~g}$ sample of $\mathrm{CaO}$ (Puratronic $₫$, 99.998\%--metals basis, excluding other alkaline earth and alkali metals 130ppm max) was enclosed in a double-walled quartz ampule. The predominant calcium isotope in naturally occurring calcium is the desired ${ }^{40} \mathrm{Ca}$, so the additional expense of an enriched sample was unnecessary. The natural abundance of calcium isotopes is shown in Table 2. The sample was pumped down in ordered minimize gaseous contaminates in the sample tube. A Co-Al neutron flux density wire (NIST SRM 953) was taped to the quartz tube in the center of the sample in order to measure neutron fluence during the irradiation. The sample was wrapped in aluminum foil with a loop at the end to allow the reactor operator to easily remove the sample for the $\mathrm{Cd}$-lined $3 \mathrm{~L}$ facility. The $\mathrm{Cd}$ liner in the $3 \mathrm{~L}$ canister was used to maximize the fraction of radioargon activity in the sample by minimizing the thermal activations of $\mathrm{Ca}$ and surrounding quartz.

The sample was irradiated for 2 hours in the Cd-lined $\mathrm{Al}$ alloy canister in the $3 \mathrm{~L}$ facility at 500 $\mathrm{kW}$. The sample and irradiation canister were allowed to decay for 6 hours before removal from the reactor. The quartz ampule was placed on a single HPGe detector 12 hours after the end of the irradiation. The sample was counted in a position about $7 \mathrm{~cm}$ away from the detector. The beginning counting intervals were shorter, which would allow the short-lived isotopes show through even with an extremely active sample. The dominant lines, especially during the early counting, were due to the activation of the quartz.

The first two counting periods showed the appearance of ${ }^{41} \mathrm{Ar}$, which was produced via the ${ }^{44} \mathrm{Ca}(\mathrm{n}, \alpha)$ pathway, shown in Fig. 1. In the subsequent counts, the count time was longer and did not show the presence of any other radioargon isotopes. The sample was counted periodically over the next week to find the signatures of other radioactive products. The $1,524.70 \mathrm{keV}$ peak of ${ }^{42} \mathrm{~K}$ was present in the first seven spectrum and was produced through the ${ }^{42} \mathrm{Ca}(\mathrm{n}, \mathrm{p})$ pathway. The peaks of ${ }^{43} \mathrm{~K}$ at $220.631 \mathrm{keV}, 372.760 \mathrm{keV}, 396.861 \mathrm{keV}, 593.390 \mathrm{keV}$, and $617.490 \mathrm{keV}$ were also present in the majority of the spectra. The only radiative capture product of $\mathrm{Ca}$ that was visible in the spectra was ${ }^{47} \mathrm{Ca}$ with a 4.536 day half-life as indicated by the $1,297.09 \mathrm{keV}$ gamma-ray peak.

\section{Reactor Model}

Using the flux profile generated by the MCNPX reactor model, shown in Fig. 2, and the CINDER90 cross-section library, collapsed cross-sections were generated for the reactions of interest.

$$
\bar{\sigma}=\frac{\sum_{i=1}^{63} \sigma_{i} \phi_{i}}{\sum_{j=1}^{63} \phi_{j}}
$$

where $\bar{\sigma}$ is the collapsed cross-section, $\sigma_{\mathrm{i}}$ is the cross-section at the energy of the ith energy bin, and $\square_{\mathrm{i}}$ is the neutron flux of the ith energy bin. 
The activities of the isotopes of interest were calculated at various time steps in order to optimize the irradiation time, shown in Fig 3. Some cross-sections were missing from CINDER90, so ENDF VII.0 cross-section libraries were used for for the calculation of ${ }^{42} \mathrm{Ca}(\mathrm{n}, \mathrm{p}){ }^{42} \mathrm{~K}$ and ${ }^{44} \mathrm{Ca}(\mathrm{n}, \alpha){ }^{41} \mathrm{Ar}$ reactions [9].

This experiment was a successful in producing a radioargon sample that is predominantly ${ }^{37} \mathrm{Ar}$ with a TRIGA reactor via the ${ }^{40} \mathrm{Ca}(\mathrm{n}, \alpha)$ pathway. With the proper detector set-up the production ratios of radioargon isotopes could be determined. This method would provide radioargon production ratios that are much closer to the underground nuclear event signature. If radioargon separation was necessary, it could be achieved through a digestion process that utilizes nitric acid. However, this experiment did not require the separation of the radioargon. Since ${ }^{37} \mathrm{Ar}$ and ${ }^{39} \mathrm{Ar}$ are difficult to measure, the induced activities of ${ }^{37} \mathrm{Ar}$ and ${ }^{39} \mathrm{Ar}$ were estimated through measurements of other activation products at the end of irradiation. Then the activity of the radioargon isotope of interest was estimated by using a production ratio based on the crosssections. The cross-sections used were the collapsed cross-sections based on the CINDER90 libraries for ${ }^{43} \mathrm{~K}$ and ${ }^{47} \mathrm{Ca}$. The energy-dependent flux weighted reaction cross-sections used in the calculations are shown in Table 2. For the upper energy dominated reactions like $(n, \alpha)$, the fission spectrum average cross-section is larger than the collapsed cross-section. However, when the reaction is dominated by thermal neutrons like a radiative capture reaction, the fission spectrum averaged cross-section is much lower than the collapsed cross-section.

The production activities were estimated using the following equation

$A_{x}\left(t_{d}=0\right)=A_{y} \frac{N_{x p} \sigma^{x p}\left(1-e^{-\lambda_{x} t_{i}}\right)}{N_{y p} \sigma^{y p}\left(1-e^{-\lambda_{y} t_{i}}\right)}$

Where $A_{x}$ is the activity of the isotope of interest $\left({ }^{37} \mathrm{Ar}\right.$ or $\left.{ }^{39} \mathrm{Ar}\right), \mathrm{A}_{\mathrm{y}}$ is the activity of the measured isotope of interest, $N_{x p}$ is the number of atoms of the precursor isotope to produce the isotope of interest $(\mathrm{X}), \sigma^{\mathrm{xp}}$ is the cross-section for the reaction pathway from isotope $\mathrm{xp}$ to $\mathrm{x}, \lambda$ is the decay constant, $t_{i}$ is the irradiation time, and $t_{d}$ is the decay time.

The estimated activities and the values from the MCNPX model are shown in Table 3. The error represented in the table is only a function of the counting and efficiency. This is a gross underestimation of the total error. The largest source of error will be the cross-section libraries, but there was not a straight forward or consistent way to calculate this error. There is also the error contribution due to the geometry of the sample and the heterogeneous distribution of the different elements within the quartz ampoule. For example, the argon isotopes would be more likely to be evenly distributed through the length of the quartz ampoule. The calcium isotopes are more likely to be situated in the bottom of the ampoule where the $\mathrm{CaO}$ powder was placed.

\section{Conclusion}


The presence of ${ }^{41} \mathrm{Ar}$ induced through ${ }^{44} \mathrm{Ca}(\mathrm{n}, \alpha)$ pathway, ${ }^{42} \mathrm{~K}$ through the ${ }^{42} \mathrm{Ca}(\mathrm{n}, \mathrm{p})$ pathway, ${ }^{43} \mathrm{~K}$ through the ${ }^{43} \mathrm{Ca}(\mathrm{n}, \mathrm{p})$ pathway and ${ }^{47} \mathrm{Ca}$ through the ${ }^{46} \mathrm{Ca}(\mathrm{n}, \gamma)$ pathway allowed for the approximation of the ${ }^{37} \mathrm{Ar}$ and ${ }^{39} \mathrm{Ar}$ activities produced. The UT TRIGA MCNPX model predicted a ${ }^{37} \mathrm{Ar}$ activity of $1.156 \times 10^{6} \mathrm{~Bq}$. Our production ratios with the experimental system estimated activities on the average of 1.83E6 Bq. The UT TRIGA MCNPX model predicted ${ }^{39} \mathrm{Ar}$ activity of $7.68 \times 10^{-2} \mathrm{~Bq}$, but the production ratios gave an average estimate of $0.122 \mathrm{~Bq}$.

The lower experimental values are partially attributed to the unusual shape of the quartz sample, which would decrease the detector efficiency. The largest difference between the production ratio derived radioargon activities and the model activities was found using the ${ }^{41} \mathrm{Ar}$ activity. The quartz ampoule remained sealed, so the distributions of activation products remain unknown. However, a few estimations were made to try to explain the deviation in activities in the generated by the production ratio UT TRIGA model calculations. Since ${ }^{41} \mathrm{Ar}$ is a gas, it is assumed that the gas moved freely through the quartz ampoule. The potassium and ${ }^{47} \mathrm{Ca}$ would be more likely to stay in the bottom of the ampoule with the white powder. Therefore, the effective length of the sample is shorter, which would improve the detection efficiency. For sample with different shapes, the efficiency calculation should consider the geometry.

The CINDER90 collapsed cross-section libraries did a better job of predicting the actual activity than the average fission spectrum reaction cross-sections. This can be seen by the closer radioargon activity calculations using ${ }^{47} \mathrm{Ca}$ and ${ }^{43} \mathrm{~K}$ activities and CINDDER 90 cross-section libraries. This could show that the ${ }^{40} \mathrm{Ca}(\mathrm{n}, \alpha)^{37} \mathrm{Ar}$ reaction cross-section should have the $1 / \mathrm{v}$ thermal relationship, which both the ROSFOND[10] and Riedmann and Purtschert [11] use. It could also show the epithermal neutrons made a significant contribution to the reaction crosssection.

The irradiation of $\mathrm{CaO}$ for ${ }^{37} \mathrm{Ar}$ production is not the optimal method for the UT TRIGA reactor. The 2 hour irradiation time and $500 \mathrm{~kW}$ power level used are the maximum time periods allowed for the Cd-lined $3 \mathrm{~L}$ facility. Also, the radioargon separation procedure would include several liquid steps using nitric acid, which would in turn produce liquid radioactive waste. The waste streams are unnecessary and difficult to store. The irradiation of calcium-containing compounds for radioargon production is a viable method for fast reactors. Future ${ }^{37} \mathrm{Ar}$ production should avoid this method considering the ease of gas irradiation using the thermal neutron spectra.

The production of ${ }^{37} \mathrm{Ar}$ produced through the irradiating calcium-containing compounds was successful. The Ar gas irradiation methods are an optimal fit for the mainly thermal flux of the UT TRIGA reactor. The computation model improved the approximation of the produced radioargon isotopes. The UT TRIGA MCNPX reactor model improved the calculation of the induced radioargon activities of the radioargon isotopes that do not decay via gamma ray emission. However, the limiting factor of this method is the cross-section libraries. Unfortunately the radioargon cross-section libraries do not agree (CINDER90 vs. JEFF 3.1). The ROSFOND data libraries [10] have incomplete cross-section libraries. 


\section{REFERENCES}

1. Abdurashitov DN, Veretenkin, EP, Gavrin VN, Gorbachev VV, Ibragimova TV, Kalikhov AV, Mirmov IN, Shikhim AA, Yants VE, Barsanov VI, Dzhanelidze AA, Zlokasov SB, Markov SYu, Shakirov ZN, Cleveland BT (2007) Phy Atomic Nuc 70:311

2. Abdurashitov JN, Gavrin VN, Mirmov IN, Veretenkin EP, Yants VE, Oshkanov NN, Karpenko AI, Maltsev VV, Barsanov VI, Trubin KS, Zlokazov SB, Khomyakov YuS, Poplavsky VM, Saraeva TO, Vasiliev BA, Mishin OV, Bowles TJ, Teasdale WA, Lande K, Wildenhain P, Cleveland BT, Elliott SR, Haxton W, Wilkerson JF, Suzuki Z, Suzuki Y, Nakahata M (2002) Nucl Phys B 110:326.

3. Barsanov VI, Dzhanelidze AA, Zlokazov SB, Kotelnikov NA, Markov SYu, Selin VV, Shakirov ZN, Abdurashitov DN, Veretenkin EP, Gavrin VN, Gorbachev VV, Ibragimova TV, Kalikhov AV, Mirmov IN, Shikhim AA, Yants VE, Klomyakov YuS, Cleveland BT (2007) Phys Atomic Nuc 70:300

4. Aaslseth CE, Day AR, Haas DA, Hoppe EW, Hyronimus BJ, Keillor ME, Mace EK, Orrell JL, Seifert A, Woods VT (2011) Nucl Instr Meth Phys Research A 652:58-61

5. Egnatuk CM, Lowrey J, Biegalski SR, Bowyer T, Haas D, Orrell J, Woods V, Keillor M (2012) J Radioanal Nucl Chem 291:257

6. Haas DA, Beigalski SR, Foltz Biegalski KM (2009) J Radioanal Nucl Chem 282:677

7. Ward RM, Biegalski SRF, Haas DA, Hennig W (2009) J Radional Nucl Chem 282:693

8. Egnatuk CM, Biegalski SR (2012) J Radioanal Chem. DOI: 10.1007/s10967-012-1981-X

9. Chadwick M, Oblozinsky P, Herman M, Greene N, McKnight R, Smith D, Young P, MacFarlane R, Hale G, Frankle S (2006) Nuclear Data Sheets, 107 (12): 2931-3060.

10. Zabrodskaya SV, Ignatyuk AV, Koscheev VN, Manokhin VN, Nikolaev MN, Pronyaev VG (2007) VANT, Nuclear Constants 1-2 3

11. Reidmann RA, Purtschert R (2011) Environ Sci Technol 45(20):8656-8664

Prepared by LLNL under Contract DE-AC52-07NA27344. 
Table 1. The advantages and disadvantages of using the different calcium-containing compounds in the Cd-lined irradiation facilty.

\begin{tabular}{|c|c|c|}
\hline $\begin{array}{l}\text { Ca } \\
\text { compound }\end{array}$ & Advantages & Disadvantages \\
\hline $\mathrm{CaO}$ & $\begin{array}{l}\text { High calcium density } \\
\text { High melting point }\end{array}$ & $\begin{array}{l}\text { Argon release requires dissolving compound } \\
\text { in nitric acid (liquid waste stream) }\end{array}$ \\
\hline Metallic & $\begin{array}{l}\text { High calcium density } \\
\text { High melting point }\end{array}$ & Extremely difficult to separate argon \\
\hline $\mathrm{CaC}_{2} \mathrm{O}_{4}$ & $\begin{array}{c}\text { Easy to extract argon (liquid } \\
\text { nitrogen-cooled charcoal trap) }\end{array}$ & $\begin{array}{l}\text { Decomposition temperature could be reached } \\
\text { in cadmium-lined 3L }\end{array}$ \\
\hline
\end{tabular}

Table 2. The percent abundance of calcium isotopes in naturally occurring calcium.

\begin{tabular}{|cc|}
\hline Ca isotope & Percent Abundance \\
\hline${ }^{40} \mathbf{C a}$ & $96.941 \%$ \\
${ }^{42} \mathbf{C a}$ & $0.647 \%$ \\
${ }^{43} \mathbf{C a}$ & $0.135 \%$ \\
${ }^{44} \mathrm{Ca}$ & $2.086 \%$ \\
${ }^{46} \mathrm{Ca}$ & $0.004 \%$ \\
${ }^{48} \mathbf{C a}$ & $0.187 \%$ \\
\hline
\end{tabular}

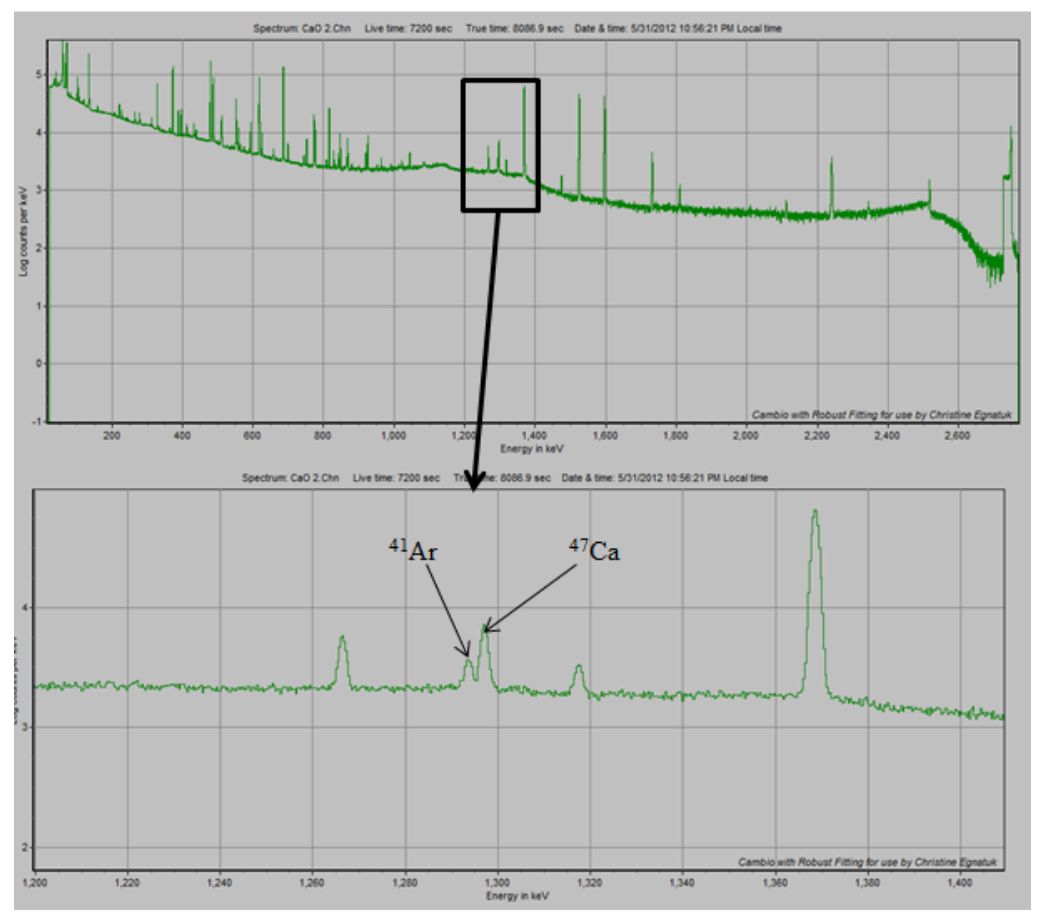

Fig 1. The gamma spectrum 


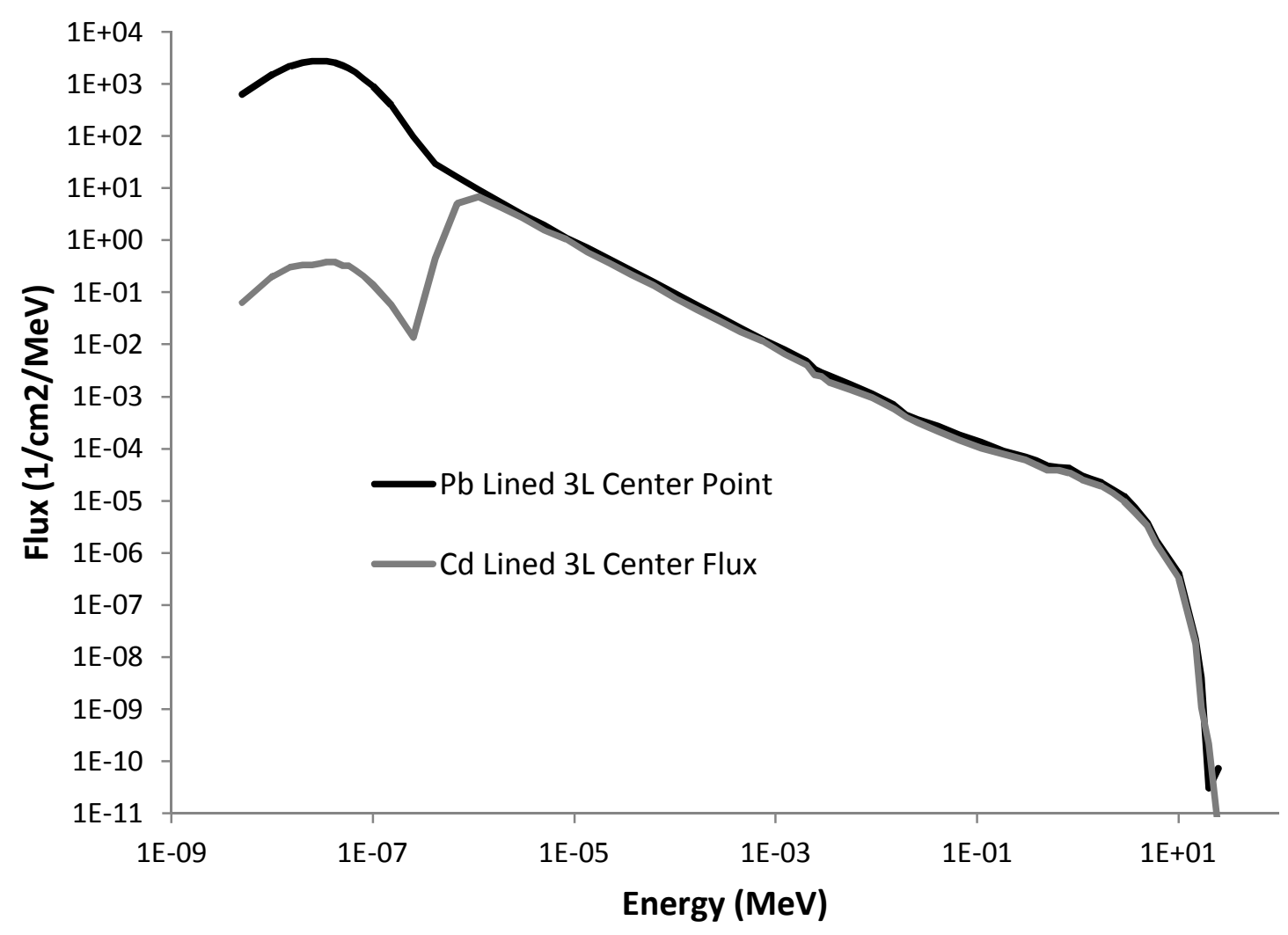

Fig 2. The flux profile of the in-core irradiation facility with the $\mathrm{Pb}$-lined and $\mathrm{Cd}$-lined irradiatior as generated by the MCNPX model. 


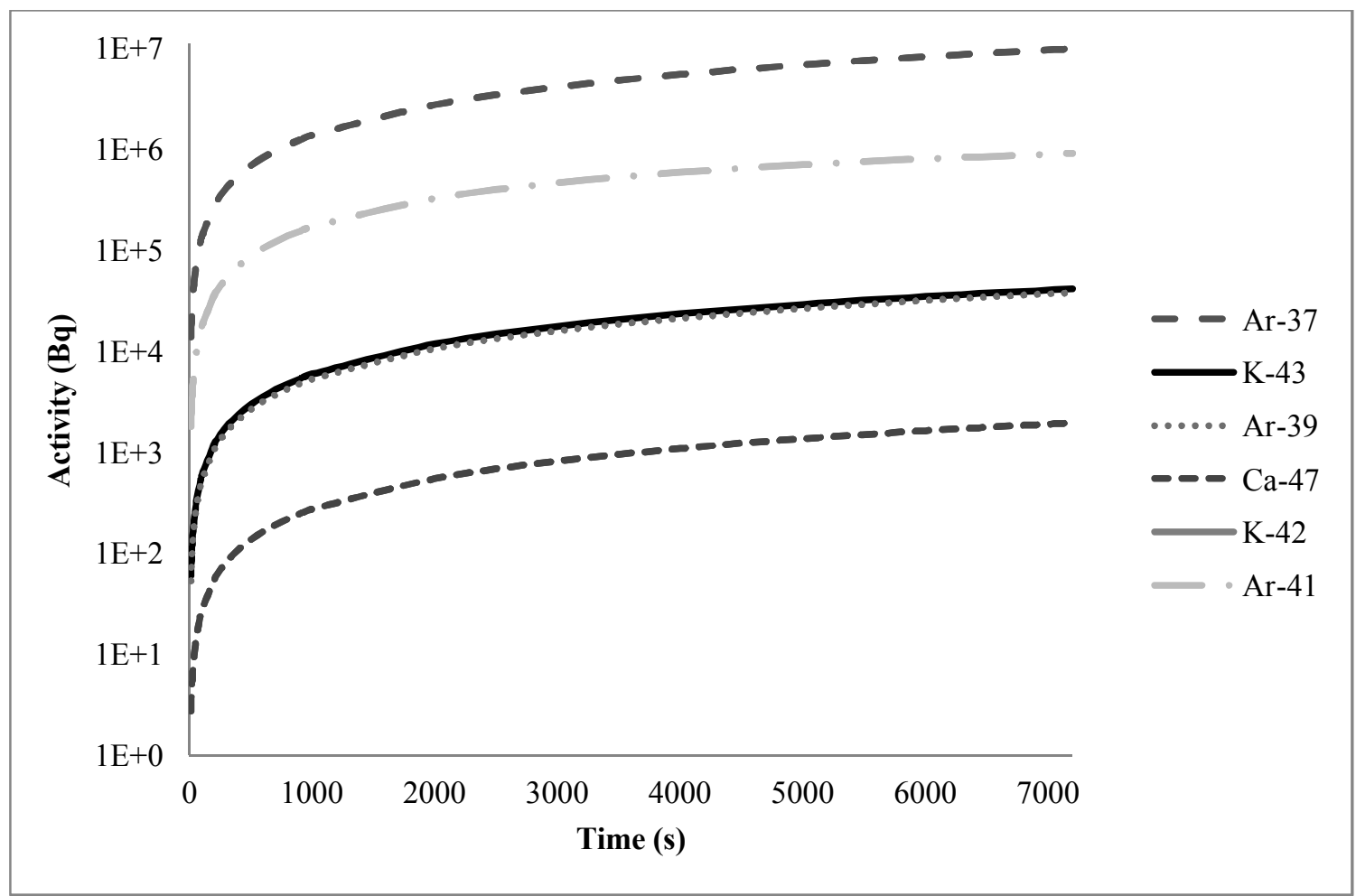

Fig 3. The activity induced of isotopes of interest at different time steps assuming a position in the Cd-lined 3L facility at $500 \mathrm{~kW}$. 
Table 2. Calcium cross-sections used to estimate the ${ }^{39} \mathrm{Ar}$ and ${ }^{37} \mathrm{Ar}$ production activities.

\begin{tabular}{|ccc|}
\hline Reaction & $\begin{array}{c}\text { Collapsed } \\
\text { cross-section }\end{array}$ & $\begin{array}{c}\text { Fission Spectrum } \\
\text { Averaged Cross-section }\end{array}$ \\
${ }^{\mathbf{4 0}} \mathbf{C a}(\mathbf{n}, \boldsymbol{\alpha}){ }^{\mathbf{3 7}} \mathbf{A r}$ & $21.2 \mathrm{mb}$ & $49.77 \mathrm{mb}$ \\
${ }^{\mathbf{4 2}} \mathbf{C a}(\mathbf{n}, \boldsymbol{\alpha}){ }^{\mathbf{3 9}} \mathbf{A r}$ & $0.594 \mathrm{mb}$ & $2.675 \mathrm{mb}$ \\
${ }^{44} \mathbf{C a}(\mathbf{n}, \boldsymbol{\alpha}){ }^{\mathbf{4 1}} \mathbf{A r}$ & $81.2 \mu \mathrm{b}$ & $212.1 \mu \mathrm{b}$ \\
${ }^{42} \mathbf{C a}(\mathbf{n}, \mathbf{p}){ }^{\mathbf{4 2}} \mathbf{K}$ & $2.42 \mathrm{mb}$ & $9.139 \mathrm{mb}$ \\
${ }^{\mathbf{4 3}} \mathbf{C a}(\mathbf{n}, \mathbf{p}){ }^{\mathbf{4 3}} \mathbf{K}$ & $1.74 \mathrm{mb}$ & $26.73 \mathrm{mb}$ \\
${ }^{46} \mathbf{C a}(\mathbf{n}, \boldsymbol{\gamma}){ }^{\mathbf{4 7}} \mathbf{C a}$ & $13.2 \mathrm{mb}$ & $172.2 \mu \mathrm{b}$ \\
\hline
\end{tabular}

Table 3. The estimated activities and the modeled activities in Bq.

\begin{tabular}{lcccc}
\hline \multicolumn{3}{c}{ Estimated Activities } & \multicolumn{2}{c}{ MCNPX model } \\
Based on & ${ }^{37} \mathbf{A r}$ & ${ }^{39} \mathbf{A r}$ & ${ }^{37} \mathbf{A r}$ & ${ }^{39} \mathbf{A r}$ \\
\hline${ }^{41} \mathbf{A r}$ & $6.51 \mathrm{E} 5 \pm 2.75 \mathrm{E} 4$ & $4.35 \mathrm{E}-2 \pm 3.52 \mathrm{E}-3$ & & \\
${ }^{42} \mathbf{K}$ & $1.28 \mathrm{E} 6 \pm 5.47 \mathrm{E} 3$ & $8.51 \mathrm{E}-2 \pm 7.00 \mathrm{E}-4$ & & \\
${ }^{43} \mathbf{K}$ & $1.30 \mathrm{E} 6 \pm 8.47 \mathrm{E} 3$ & $8.66 \mathrm{E}-2 \pm 5.66 \mathrm{E}-4$ & $1.15 \mathrm{E} 6$ & $7.68 \mathrm{E}-2$ \\
${ }^{47} \mathbf{C a}$ & $4.08 \mathrm{E} 6 \pm 1.01 \mathrm{E} 05$ & $2.72 \mathrm{E}-1 \pm 3.52 \mathrm{E}-3$ & & \\
\hline
\end{tabular}

